\title{
Gas Turbine Health State Determination: Methodology Approach and Field Application
}

\author{
Michele Pinelli, Pier Ruggero Spina, and Mauro Venturini \\ Dipartimento di Ingegneria, Università degli Studi di Ferrara, Via G. Saragat, 1-44122 Ferrara, Italy \\ Correspondence should be addressed to Mauro Venturini, mauro.venturini@unife.it
}

Received 30 September 2011; Accepted 3 November 2011

Academic Editor: Rainer Kurz

Copyright () 2012 Michele Pinelli et al. This is an open access article distributed under the Creative Commons Attribution License, which permits unrestricted use, distribution, and reproduction in any medium, provided the original work is properly cited.

A reduction of gas turbine maintenance costs, together with the increase in machine availability and the reduction of management costs, is usually expected when gas turbine preventive maintenance is performed in parallel to on-condition maintenance. However, on-condition maintenance requires up-to-date knowledge of the machine health state. The gas turbine health state can be determined by means of Gas Path Analysis (GPA) techniques, which allow the calculation of machine health state indices, starting from measurements taken on the machine. Since the GPA technique makes use of field measurements, the reliability of the diagnostic process also depends on measurement reliability. In this paper, a comprehensive approach for both the measurement validation and health state determination of gas turbines is discussed, and its application to a $5 \mathrm{MW}$ gas turbine working in a natural gas compression plant is presented.

\section{Introduction}

Maintaining high levels of availability and reliability is an essential objective for all production units, especially for those that are subject to high costs due to loss of production. Nonscheduled stops due to unforeseen faults cause relevant costs related to the reduction or the interruption of the process and to the consequent repairing actions. For this reason, in strategic applications, stand-by machines are usually required to ensure the desired level of availability.

In the last decades, gas turbines have been more and more used either for power generation or as mechanical drive (e.g., in natural gas compression plants), thanks to their favorable characteristics with respect to other technologies, such as low emissions and high availability and reliability. In particular, the latter issues represent winning features of gas-turbine-based power plants. Hence, in order to utilize these systems as effectively as possible, the management of machine maintenance must be optimized.

The optimization of maintenance management, which should lead to cost saving and increase in machine availability, can be performed by supporting gas turbine preventive maintenance (which comes from manufacturer experience in terms of component life and performance degradation versus working hours and is performed according to a priori schedules, regardless of the effective gas turbine health state) with on-condition maintenance, which consists of "ad hoc" actions descending from gas turbine actual operating state [1-7]. Therefore, On-condition maintenance requires up-todate knowledge of the machine health state in real time.

One of the most successful approaches for gas turbine health state determination consists of the application of Gas Path Analysis (GPA) techniques, which use a physical thermodynamic model of the machine. Linear GPA techniques have been developed and applied since the seventies [8], while nonlinear GPA techniques have been applied since the nineties [9-12].

As an alternative to physics-based methodologies, diagnostic information can also be obtained through black-box models $[13,14]$, which usually prove successful and robust [15].

In case the machine under investigation is often operated under transient conditions, steady-state models (e.g., GPA models) cannot be used, and dynamic models have instead to be applied. In this field, the authors developed several simulation models, both through a physics-based approach [16-21] and through a black-box approach [22, 23]. 
In this paper, a nonlinear GPA technique, together with its potential and limitations, is presented. The GPA-based diagnostic process uses gas turbine field measurements to determine, by means of a gas turbine thermodynamic cycle model (cycle program (CP)), the actual values of the parameters that are indices of the gas turbine health state (Health Indices (HIs)), such as efficiencies, characteristic flow passage areas and pressure drops along the gas path $[9,12,24-27]$. One of the main effects of deterioration and fault is the modification of compressor and turbine performance maps. Since detailed information about actual modification of component maps is usually unavailable, the effects of deterioration and fault are simulated by scaling the map itself, that is, by calculating the map scaling factors through the inverse solution of the $\mathrm{CP}$, in order to reproduce the measurements taken on the gas turbine $[9,12]$.

Recently, the authors developed a stage-by-stage model to investigate the effects of compressor and turbine stage deterioration [28]. This model uses generalized stage performance curves matched by means of a stage-stacking procedure [29] and was also successfully applied for wet compression modeling $[30,31]$. Moreover, the analysis of stage performance deterioration was carried out by means of CFD simulations [32-35]. The CFD approach allows to overcome the lack of experimental data necessary to correlate measurements, HI variations, and causes of degradation. Some experimental findings were reported by the authors in [36-38].

In this paper, a GPA tool, developed by the authors [12] and validated through testbench measurements [39], is used. By comparing the actual and the expected values of the HIs, it is possible to determine (i) how far the actual machine operating condition is from the expected one, (ii) which components are degraded, and (iii) the causes of malfunctioning.

One of the most critical problems that has to be faced when GPA techniques are applied is the reliability of the information that can be obtained, which depends on several factors $[40,41]$.

(i) Capability of the CP to accurately reproduce the actual gas turbine thermodynamic cycle [42].

(ii) Accuracy of field measurements. To minimize measurement error effects, it is usually advisable to support GPA techniques by means of methodologies for measurement validation [43-48]. In this way, it is possible (i) to determine whether a measurement set is reliable and, if it is recognized, that an outlier is present, and (ii) to adapt the technique for the health state determination, for example, by excluding such a measurement set from the diagnostic process.

(iii) Limited availability of measured quantities on the gas turbine, which causes problems to correctly assess the actual health state. In fact, for example, a single failure can lead to the same effects (same measurement variations) as those that can be induced by a series of concurrent failures. Furthermore, some typologies of failures, as clearance increase or combustor malfunctioning, are usually detectable with difficulty [12]. So, only an adequate number of measured quantities can help to distinguish among different failures.

(iv) Some of the HIs to be estimated have to be kept constant during the calculations. In fact, since the number of the available measured quantities is usually lower than the number of HIs that have to be determined, some of them have to be considered constant. This causes an estimation error on the HIs considered as problem variables, when variations due to aging or deterioration occur on the HIs which were considered as fixed HIs [40, 41].

Thus, methodologies for the improvement in HI determination accuracy are required [43, 44, 49-52]. In particular, since the methodology makes use of field measurements, the reliability of the diagnostic process also depends on measurement reliability. For this reason, two techniques for measurement validation are presented in the paper: the first one is based on the use of acceptability bands [43, 53], while the other uses statistical-based methods for outlier identification [44]. Analytical redundancy techniques for sensor fault detection and isolation can also be used [54]. In any case, if there is insufficient data or measurement accuracy is low, a "reality check" should be always made to verify plausibility of the information obtained through the GPAbased tool.

In this paper, a comprehensive methodology developed by the authors for both measurement validation and health state determination of gas turbines is presented. The methodology is applied to a $5 \mathrm{MW}$ gas turbine working in a natural gas compression plant. Finally, this paper illustrates the main features of a software, which was implemented in the considered compression plant to automate the presented methodology.

\section{Methodology for Measurement Validation and Health State Determination of Gas Turbines}

The methodology for measurement validation and health state determination of gas turbines requires the availability of a CP, which should reproduce the particular gas turbine under consideration as accurately as possible. Two situations can occur:

(1) The cycle deck developed by the manufacturer is available. This CP reproduces a gas turbine type, which presents average characteristics among gas turbine units of the same model.

(2) A generalized CP is available. In this case, the program has to be tuned to reproduce the machine type under investigation, for instance, by using the performance curves supplied by the manufacturer to the user.

In any case, both the cycle deck and the generalized $\mathrm{CP}$ have to be tuned in order to represent the particular gas turbine 


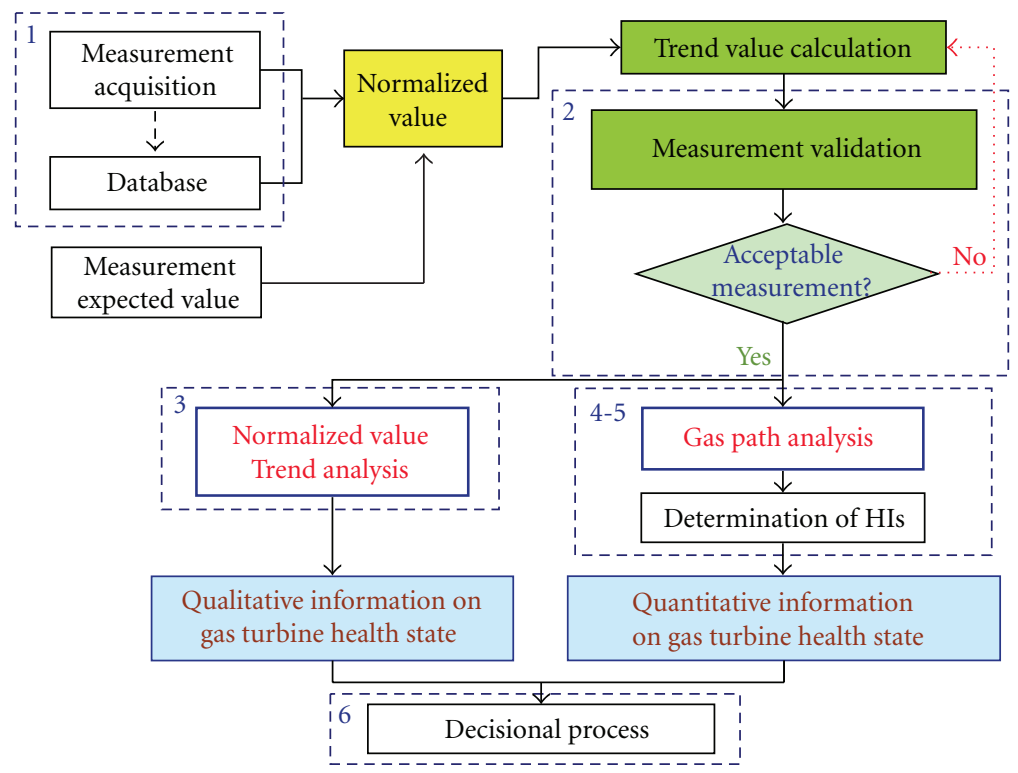

Figure 1: Comprehensive methodology for measurement validation and health state determination of gas turbines.

unit under consideration. CP tuning procedure is reported in detail in [55].

A low number of measured quantities is usually available on gas turbines in field operation. This fact limits the number of HIs that can be determined through the GPA method. Therefore, the optimal set of HIs, that can be determined by the set of available measurements, has to be identified. This requires an a priori optimized selection of the HIs which have to be considered as problem variables and of the ones to be kept constant during the calculation $[41,43,52]$.

Once a CP is tuned on the particular gas turbine and the optimal set of HIs is identified, the main steps of the comprehensive methodology for measurement validation and health state determination are sketched in Figure 1 and reported below.

(1) Acquisition of field measurements and storage on a historic database, to perform off-line data processing.

(2) Measurement validation. This allows the identification of measurements that have a level of uncertainty higher than a fixed threshold. Thus, the measurement set can be excluded from the gas turbine diagnostic process, to avoid an incorrect evaluation of the machine health state.

(3) Analysis of the normalized measurement trend (trend analysis). This analysis is required for measurement validation and also provides useful information for the determination of gas turbine health state, so improving the results obtainable by using the GPA technique alone $[43,53]$.

(4) Use of acceptable data to perform gas turbine health state determination, which consists in the determination of gas turbine HIs by using a GPA-based technique.

(5) Improvement of the diagnostic process through the determination of a higher number of gas turbine HIs by considering more than one operating point (multipoint analysis). In fact, the multiple operating point analysis allows the determination of a number of HIs higher than available measurements, since it compensates for the lack of measurements with the measurements taken at different operating points [24, 56].

(6) Decisional process, which consists of the identification of unacceptable measurements, the planning of the machine stop for maintenance, on the basis of the values of machine HIs, the possibility of on-line actions, such as compressor washing, the adaptation of the gas turbine control logic to its actual health state, and, in the worst case, the immediate stop of the machine.

A software that automates the described methodology may be very helpful as a decision support tool for both plant director and maintenance personnel [57]. Artificial intelligence techniques may help in focusing on the most significant information for improving the diagnostic process and maintenance practices [58]. Moreover, prognostics methodologies would allow to forecast degradation evolution over time, based on current diagnostic state $[59,60]$, to optimize both production and maintenance, from both a technical and an economical point of view. In a wider sense, making prognostics, based on understanding machine deterioration and aging, may allow the estimation of machine remaining useful life.

\section{Methodology for Measurement Validation}

In this paper, two techniques are considered for measurement validation, both applied to the normalized measurement trend. Measurement normalization is performed by dividing each measured value by its expected value calculated 
in the same ambient and load conditions, in order to render measurements comparable to each other, though collected in different ambient and load conditions. Such expected value can be calculated by using a CP or functional relations. While the CP is rarely available to gas turbine users, functional relations can be obtained by only using measurements taken along the gas path and thus the user can always apply this methodology.

The functional relations can be obtained through identification techniques, as for instance by using a linear regression procedure [53] or neural networks $[61,62]$. The tuning of the models requires the identification of a baseline condition across gas turbine life (e.g., the condition after overhaul maintenance). In this condition, some measurement sets taken at different loads and ambient conditions have to be available. Starting from these sets of measurements it is possible to establish relations in the form $Q_{m}=F\left(Q_{\mathrm{wp}}\right)$. The relations obtained relate thermodynamic measurements $Q_{m}$ (such as pressure and temperature at the compressor outlet) to ambient and load conditions $Q_{\mathrm{wp}}$ (ambient pressure and temperature, relative humidity, rotational speeds, and power output) over the entire gas turbine operating range. The identification procedure has to be performed once for each $Q_{m}$ measured quantity and has to be updated when the chosen baseline condition can be considered no longer representative for the engine. The obtained relations can be then used to normalize each measurement.

3.1. Measurement Acceptability Bands. Once measurements are normalized and the trend over time of each measured quantity is determined, measurement validation can be performed through measurement acceptability bands $[43,53]$ : a measurement lying within these bands will be considered acceptable, otherwise not. Band amplitude can be calculated by considering the following contributions.

(a) Measurement accuracy, that can be taken into account by considering band amplitude equal to measurement uncertainty.

(b) An engine fault, which may affect the value of the measurements along the gas path.

(c) Measurements noise along the data acquisition system. This error is usually included within measurement accuracy.

(d) Errors due to the CP accuracy. In fact, the CP is usually tuned on the engine type and not on the specific unit. This leads to an estimation error on the expected value of measurements and so to an error in the normalization process.

For the calculations performed in this paper, the uncertainty " $d$ " was not considered since the CP was tuned on the specific unit and, therefore, this source of error was considered negligible. Two bands were instead considered: the first takes into account measurements uncertainty (contribution "a"), while the second considers the variation of the measurement due to an engine fault (contribution "b"). The total band amplitude is the sum of these two contributions.
Therefore, it is possible to identify three cases to establish whether a measurement is acceptable.

(i) Value beyond measurements accuracy.

(ii) Value out of measurements accuracy, but within the maximum estimated variation of the measurement due to a fault. A measurement can lie in this region either because of sensor fault or because of an incipient engine fault. In this situation, to obtain significant information, it is necessary to consider the engine behavior before and after the anomalous value and data have to be processed by the diagnostic tool.

(iii) Value out of the maximum variation due to a fault. The measurement should not be processed by the diagnostic tool since it is identified as an outlier.

As anticipated, the bands have to be referred to as reference value. The trend value of the normalized measurements seems a reasonable choice, since, in this manner, measurement variations due to aging can be taken into consideration.

3.2. Statistical-Based Method for Outlier Identification. An alternative way for measurement validation is the analysis of the statistical distribution of the normalized measurement trend in order to detect outliers. A wide number of techniques for outlier detection exist in the literature. In gas turbine applications, practical and easy-to-use techniques such as parametric test methodologies seem to offer a compromise solution with respect to simplicity and robustness [44].

A parametric test methodology is based on the definition of a test criterion. For any given element $x_{i}$ of an $N$ dimensional sample, a test criterion can be written as

$$
\frac{\left|x_{i}-x_{m}\right|}{S} \geq k, \quad i=1, \ldots, N
$$

where $x_{m}$ is the mean of the sample and $S$ is the standard deviation. In the most general case, the coefficient $k$ is a function of the sample size $N$ and of the level of significance $\alpha$. The latter parameter has to be chosen a priori and represents the probability of rejecting a good point. For practical purposes, three levels of significance are usually considered, namely $\alpha=1 \%, 2 \%$, and 5\%. This means, for example, that if $\alpha=5 \%$ is considered, the odds against rejecting a good point are 20 to 1 (or less).

If (1) applies, $x_{i}$ is to be considered an outlier. Different methods, based on (1), and characterized by different assumptions for the coefficient $k$, are available in the literature (e.g., the Thompson method, and the Grubbs method, the Chauvenet criterion).

These "traditional" methods proved only partially effective and not very robust for gas turbine data [44], in particular when data trends are not constant over time, such as in the case of measurements taken during a long period of time on a gas turbine. In order to overcome some of the limitations of these methods, a new method was developed [44]. The method is based on the application of a test criterion in the form of (1), but both the left-hand side term and the coefficient $k$ are modified to meet the requirements that have been highlighted. The specificity of the method 
is that the coefficients introduced account for decreasing or increasing data trends, although they are also correctly defined when constant over time data trends are considered.

In other words, the new coefficients allow the test criterion to take the behavior-in-time of the considered quantity into account. In the new formulation, the test criterion is defined as

$$
\frac{\left|x_{i}-x_{m}\right|}{k_{B} S} \geq t_{\alpha} k_{A}, \quad i=1, \ldots, N
$$

The coefficient $k_{A}$ is defined as

$$
k_{A}=1+\frac{\lim _{N \rightarrow \infty} t_{\alpha}^{2}+1}{4 N} .
$$

This coefficient is defined in such a manner as to tend to one when $N$ tends to infinity. The coefficient $t_{\alpha}$ represents the value of the quantile corresponding to a certain level of significance related to the Gaussian distribution. The coefficient $k_{B}$, defined as

$$
k_{B}=(1+N)^{1 / N}\left(1+\left|S_{\mathrm{ov}}-S_{i}\right|\right),
$$

allows the scatter of the considered sample to be taken into account. In fact, a relationship between the overall standard deviation $S_{\mathrm{ov}}$ and the standard deviation calculated by considering the data range $[1, i]$, namely $S_{i}$, where $i$ is the current data, which is under investigation, is introduced in the test criterion. In this manner, the left-hand side term of (2), instead of being constant as in the Thompson, Grubbs, and Chauvenet methods, is updated at each step and, thus, the behavior-in-time of the quantity is taken into account. However, this requires the availability of all data for the time period under examination, in order to estimate data overall standard deviation $S_{\mathrm{ov}}$, and, thus, $k_{B}$ dependence with time can be evaluated only in the case of data off-line processing. Otherwise, if data are processed on line, $k_{B}$ only depends on sample size $N$, since, in this case, $S_{\text {ov }}$ equals $S_{i}$.

\section{Methodology for Health State Determination of Gas Turbines}

4.1. Single Operating Point Analysis. Gas turbine operating state determination consists of the assessment of the modification, due to deterioration and fault, of performance and geometric data characterizing the machine components. One of the main effects of deterioration and fault is the modification of compressor and turbine performance maps. Since detailed information about actual modification of component maps is usually unavailable, many authors simulate the effects of deterioration and fault by scaling the map itself, that is, by multiplying the maps in new and clean condition by scaling factors $F$ point by point $[9,12,56]$. Different scaling factors can be used; compressor and turbine maps are usually scaled by multiplying efficiency and corrected mass flow rate, at constant pressure ratio (or equivalent parameter, such as the ratio between isentropic enthalpy variation and turbine inlet temperature) and at constant corrected rotational speed $[9,12,56]$. The modification of compressor and turbine performance maps with respect to new and clean condition due to actual deteriorations and faults can be assessed by calculating the map scaling factors $F$ in order to reproduce the measurements taken on the gas turbine $[9,12,56]$.

Therefore, the scale factors of efficiency and corrected mass flow of compressor and turbines can be assumed as characteristic parameters of compressor and turbine health state. In addition to these parameters, two other important parameters for representing the gas turbine health state are the combustor efficiency and pressure drop. In particular, the combustor efficiency accounts for thermal losses along the gas path, which are considered as a fixed constant percentage of the thermal power introduced by the fuel, while the combustor pressure drop is usually defined as a constant percentage of the total pressure at the combustor inlet. This type of parameters is sensitive to the gas turbine health state, while it is not dependent on the gas turbine operating point. Parameters with this characteristic are usually called health indices (HIs).

The HIs can be calculated by solving in inverse mode the $\mathrm{CP}$ in order to reproduce the measurements taken on the gas turbine. In fact, the values of the measurable variables computed by the CP $Q_{m, c}$ are a function of the values assumed both by the health indices $X$ and by the variables that unequivocally determine the operating point at which the gas turbine is working $Q_{w p}$ :

$$
Q_{m, c}=f\left(X, Q_{\mathrm{wp}}\right) \text {. }
$$

By inverting (5), it is possible to calculate $X$ starting from the measured variables:

$$
X=f\left(Q_{m}, Q_{w p}\right) .
$$

The solution of (6), usually called "inverse" solution, has been performed by the authors through a minimization technique which determines the values of HIs that minimize the sum of the square differences, between measured and computed values of the measurable variables [12]. This problem is solved by using a nonlinear algorithm, which minimizes the objective function:

$$
f_{\mathrm{ob}}\left(X_{1}, \ldots, X_{N_{X}}\right)=\sum_{i=1}^{N_{m}} w_{i}\left(\frac{Q_{m, c}-Q_{m}}{Q_{m}}\right)_{i}^{2},
$$

where $X_{i}\left(i=1, \ldots, N_{x}\right)$ are the unknown values of HIs, $\left(Q_{m, c}\right)_{i}$ and $\left(Q_{m}\right)_{i}$ are the computed estimates and the measured values of the measurable quantities, respectively, and $w_{i}$ are the weights which can be assigned to each term of the objective function.

The minimization algorithm which was used is included in the IMSL math library [63] and was successfully utilized to solve the gas turbine mathematical model $[3,11,12,24,29$, $39,41,57,64]$. Once the HIs are calculated, the gas turbine health state is determined by evaluating the variations of the HI values with respect to the expected values in the "new and clean condition." This allows the faulty component to be localized and malfunctions to be identified and quantified.

From (6), the number and type of gas turbine HIs that can be determined for each operating point (i.e., for each 


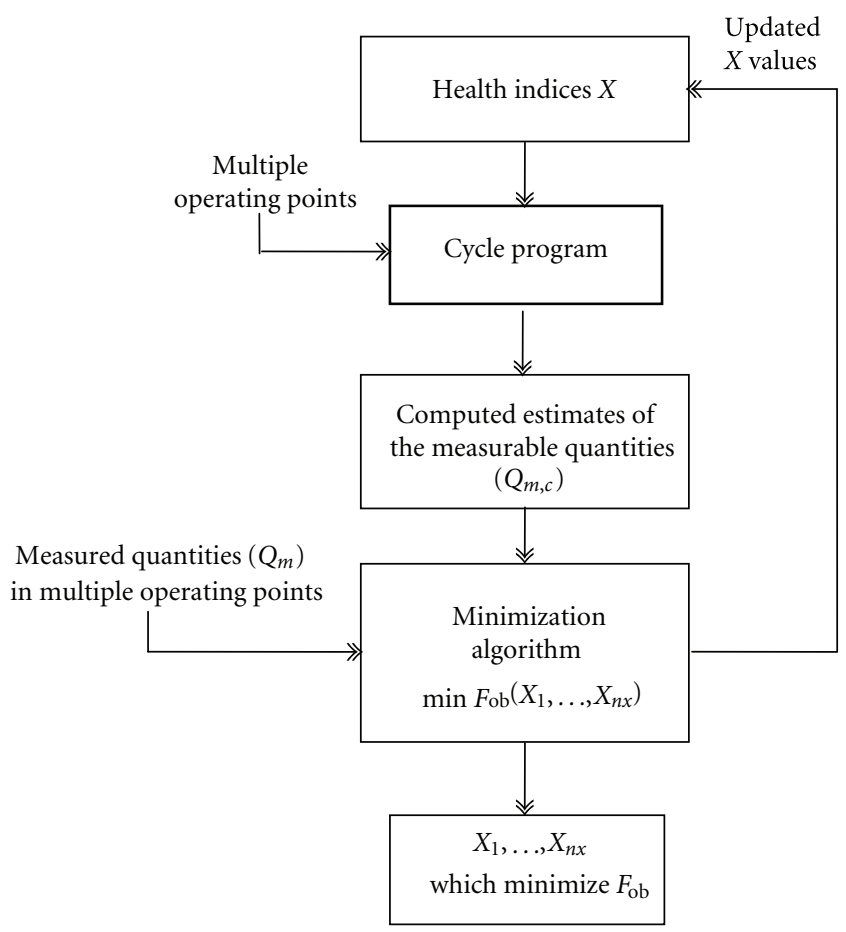

FIgURE 2: Multiple operating point analysis.

set of $Q_{w p}$ ) depend on the number and type of equations, which, in turn, depend on the number and type of the available measured quantities. In particular, the number of HIs is usually equal to the number of the $Q_{m}$ measured variables. Thus, since the number of the $Q_{m}$ available measured quantities is usually lower than the number of HIs to be estimated, some of them have to be kept constant during the calculations. Therefore, variations due to aging or deterioration which, in the actual machine, occur on the HIs, which were considered as fixed HIs, will cause an estimation error on the HIs to be determined [40,41].

4.2. Multiple Operating Point Analysis. A direct consequence of (6) is that more equations can be obtained by using more than one $Q_{w p}$ set. Thus, the number of gas turbine HIs that can be determined also depends on the number of gas turbine operating points (i.e., number of $Q_{w p}$ sets) $[24,56]$. Therefore, by using multiple operating points it is possible to evaluate a number of HIs higher than the number of the available $Q_{m}$ measured quantities.

Therefore, as made in the case of single operating point analysis, the solution of the system of equations obtained by using more than one $Q_{w p}$ set in (6) was performed through a minimization technique, which determines the values of HIs that minimize the sum of the square differences, between measured and computed values of the measurable variables in all the operating points considered. The objective function to be minimized becomes

$$
f_{\mathrm{ob}}\left(X_{1}, \ldots, X_{N_{X}}\right)=\frac{1}{N_{\mathrm{OP}}} \sum_{j=1}^{N_{\mathrm{OP}}}\left[\sum_{i=1}^{N_{m}} w_{i}\left(\frac{Q_{m, c}-Q_{m}}{Q_{m}}\right)_{i}^{2}\right]_{j},
$$

where $X_{i}\left(i=1, \ldots, N_{x}\right)$ are the unknown HIs, $\left(Q_{m, c}\right)_{i}$ and $\left(Q_{m}\right)_{i}$ are the computed estimates and the measured values of the measurable variables respectively, and $w_{i}$ are the weights assigned to each term of the objective function.

The main steps of the multiple operating point technique are sketched in Figure 2. The adopted minimization algorithm is the same as for that the single point analysis [63].

The different operating points have to be taken within a small time interval (for instance during the same day) so that the gas turbine health state can be considered the same for all the operating points and, thus, the solution $X$ of (6) is the same for all the operating points. The most suitable choice of the operating points to be used was analyzed in [24].

\section{Application of the Methodology to Gas Turbines Running in a Natural Gas Compression Plant}

The comprehensive methodology for measurement validation and health state determination of gas turbines was applied to two compressor drive gas turbines working in a natural gas compression plant. In this plant, the pressure of the gas coming from the Adriatic Sea reservoirs is raised to the value required by the Italian Gas Supply Company by using four compression systems. Two of them are driven by $5.2 \mathrm{MW}$ regenerative cycle two-shaft industrial gas turbines with variable power turbine nozzles $(\mathrm{VN})$ and two by $1.2 \mathrm{MW}$ simple cycle two shaft gas turbines. The methodology was applied to the two $5.2 \mathrm{MW}$ gas turbines whose lay out is shown in Figure 3.

In any case, the methodology is completely general. In fact, it was also successfully applied to a single shaft gas 


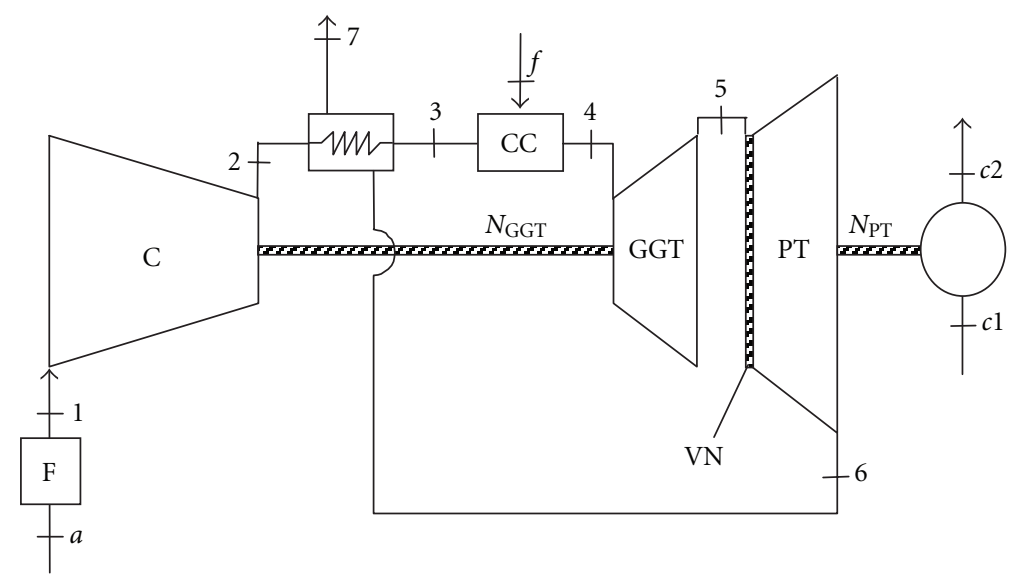

FIgURE 3: Layout of the 5.2 MW two-shaft regenerative cycle gas turbine.

TABLE 1: Available measurements.

\begin{tabular}{lc}
\hline$Q_{\mathrm{wp}}$ measurements & $Q_{m}$ measurements \\
\hline$T_{1}:$ comp. inlet temp. & $p_{2}:$ comp. outlet pressure \\
$p_{a}:$ ambient pressure & $T_{2}:$ comp. outlet temp. \\
$\mathrm{RH}:$ relative humidity & $T_{6}$ : power turb. outlet temp. \\
$\Delta p_{a-1}:$ filter pressure drop & \\
$\mathrm{VN}:$ var. nozzle position & Other measurements \\
$N_{\mathrm{GGT}}$ : gas gen. turb. rot. speed & $T_{3}:$ recuperator outlet temp. (air side) \\
$N_{\mathrm{PT}}:$ power turbine rot. speed & $T_{7}:$ recuperator outlet temp. (gas side) \\
$P_{\mathrm{PT}}:$ power output (calculated from measured $T_{c 1}, T_{c 2}$ and $\left.M_{c 1}\right)$ &
\end{tabular}

turbine working in a cogenerative combined power plant [65].

Table 1 reports the measurements available on each 5.2 MW gas turbine system. As can be seen from Table 1, some very important measurements for a reliable diagnosis analysis are not available. They are the fuel mass flow rate (at present, only the total fuel mass flow feeding both the 5.2 MW gas turbines is measured), the pressure and temperature between the gas generator and the power turbine $\left(p_{5}\right.$, $T_{5}$ ), the air side and exhaust side regenerator pressure drops $\left(\Delta p_{2-3}, \Delta p_{6-7}\right)$, and the air inlet mass flow rate $\left(M_{1}\right)$.

The methodology was applied to a poorly instrumented plant, since it represents a selective test for verifying the capabilities of the proposed diagnostic system. Moreover, poor instrumented plants are highly widespread and, thus, the application to such cases seems particularly interesting.

Before applying the methodology for gas turbine health state determination, a generalized CP developed by the authors was tuned to reproduce the gas turbine under consideration. This was made by using as reference values the performance curves provided by the gas turbine manufacturer to the user.

These curves provide the compressor outlet pressure $\left(p_{2}\right)$ and temperature $\left(T_{2}\right)$, power turbine outlet temperature $\left(T_{6}\right)$, fuel and inlet air mass flow rates $\left(M_{f}\right.$ and $\left.M_{1}\right)$ at various gas turbine working points. After the tuning, the program estimates manufacturer data with a maximum error usually lower than $1 \%[3]$.
The following step of the procedure requires the identification of the optimal combination measurements/HIs. As shown in Table 1, there are only three available measurements to perform the operating state determination: $p_{2}$, $T_{2}$, and $T_{6}$. In fact, the other measurements are used to define the working point. Therefore, only three HIs can be unequivocally determined. The optimal HIs set (identified according to $[43,52]$ ), which can be determined by using the set of available measurements, is composed of the following HIs: compressor efficiency $\left(\eta_{\mathrm{C}}\right)$, corrected mass flow $\left(\mu_{\mathrm{C}}\right)$, and gas generator turbine efficiency $\left(\eta_{\mathrm{GGT}}\right)$.

Phase 1: Acquisition and Storage of Field Measurements. The available data were gathered once a day manually by an operator. This caused the presence of a number of wild points originating from sources such as reading errors, data taken in unstable and/or not representative conditions, and so forth, which were difficult to detect. This may be a common situation in practice and thus it could represent a test bed for measurement validation techniques. The results reported refer to data acquired in the period from 2nd November 1999 to 16 th January 2000 on one of the two gas turbines under investigation.

Phase 2: Measurement Validation. Measurement validation was performed by means of the two previously described techniques, both applied to the normalized measurement trend. Measurement normalization was performed by 
TABLE 2: Band amplitude: measurements accuracy and total band amplitude.

\begin{tabular}{lcr}
\hline Measured Quantities & Measurements accuracy [\% of reference value] & Confidence band [\% of trend value] \\
\hline$T_{2}$ & \pm 0.85 & {$[-1 ;+5.5]$} \\
$p_{2}$ & \pm 1.00 & {$[-4 ;+3]$} \\
$T_{6}$ & \pm 0.75 & {$[-1 ;+5.5]$} \\
\hline
\end{tabular}

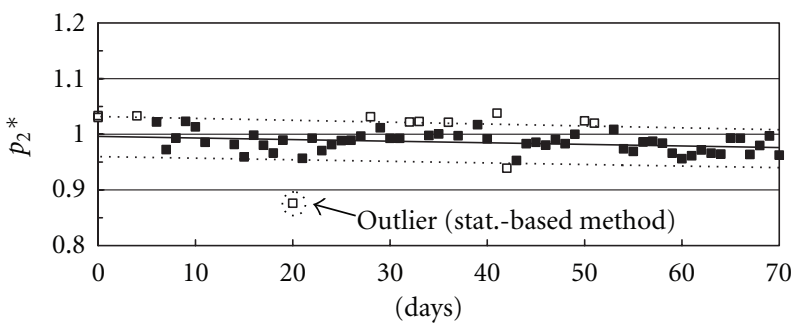

- Acceptable data

- Unacceptable data (acc. bands)

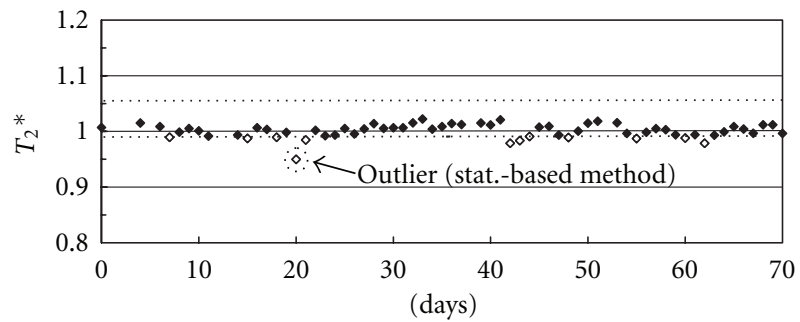

- Acceptable data

- Unacceptable data (acc. bands)

(a)

(b)

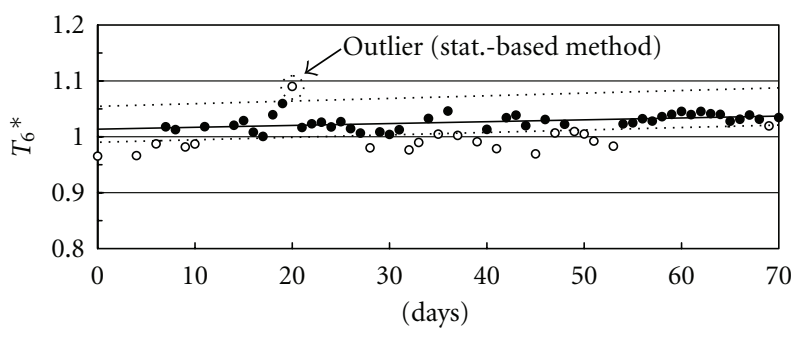

- Acceptable data

- Unacceptable data (acc. bands)

(c)

FIgURE 4: Normalized values of compressor outlet pressure $\left(p_{2}{ }^{*}\right)$, compressor outlet temperature $\left(T_{2}{ }^{*}\right)$ and power turbine outlet temperature $\left(T_{6}{ }^{*}\right)$ versus time.

dividing each measured value by its expected value calculated in the same ambient and load conditions, by using the CP tuned on the machine under consideration. Measurement acceptability bands were applied to the normalized measurement trend and take into account both measurement uncertainty and maximum variations of measurements due to faults, according to Table $2[43,53]$.

Measurement uncertainty bands (second column in Table 2) were set according to the sensor accuracy reported in [66] and by considering the case in which the measurements were taken in the field with standard machine instrumentation during normal operation and not when conducting an acceptance test. In order to establish the amplitude of the bands deriving from measurement variation due to faults, the CP tuned on the considered machine was used to simulate some of the most common faults that can occur on a gas turbine (compressor fouling, compressor mechanical damage, gas generator turbine mechanical damage, gas generator turbine erosion, and power turbine erosion) [43]. Faults are to be considered as sudden faults, since measurement variations due to aging or deterioration are considered through the normalization process. Figure 4 reports the normalized values of the compressor outlet pressure $\left(p_{2}\right)$ and temperature $\left(T_{2}\right)$ and of the power turbine outlet temperature $\left(T_{6}\right)$ versus time. The solid line indicates measurement trend over time, while the dashed lines are the acceptability bands. The figure highlights:

(i) the decreasing trend of the outlet compressor pressure and the slightly increasing trend of the compressor outlet temperature. These symptoms may be attributed to compressor fouling The increasing trend of the power turbine outlet temperature can be also observed.

(ii) the measurement scattering due to the uncertainties in field measurement readings.

(iii) the unacceptable measurements according to the use of acceptability bands (white symbols). Moreover, the application of the statistical-based method for outlier identification reveals that only one measurement set (i.e. the one at day no. 20) can be considered unacceptable also by using this second method. Thus, the use of the statistical-based method reveals less restrictive than the use of acceptability bands. 


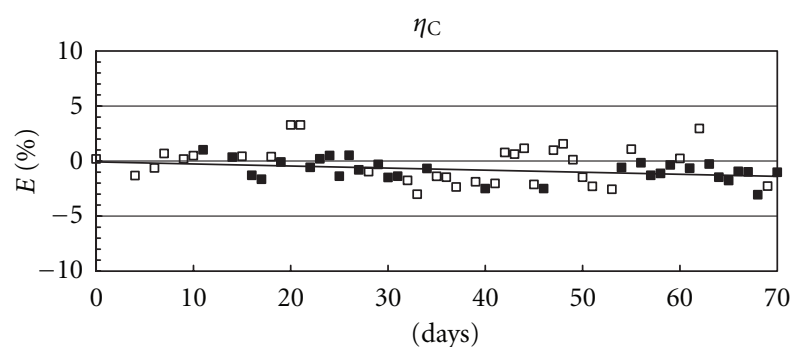

- Acceptable data

- Unacceptable data

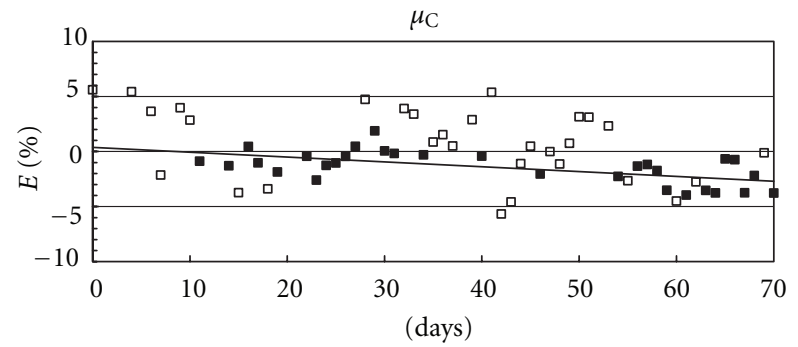

- Acceptable data

- Unacceptable data (acc. bands)

(b)

(a)

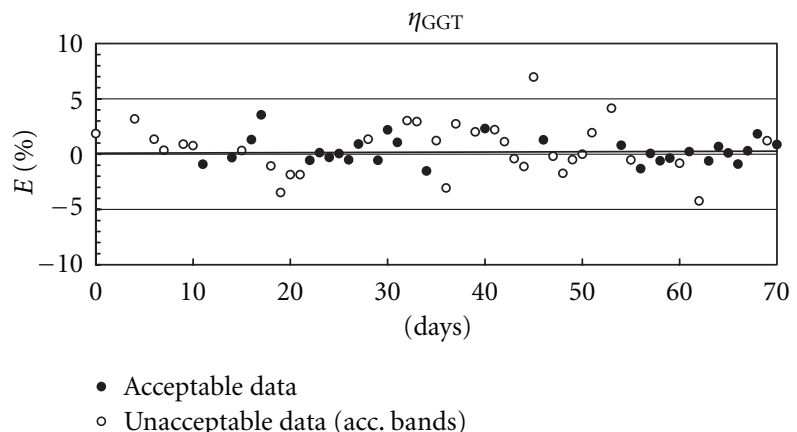

(c)

FIGURE 5: Computed and reference value percentage variations for compressor efficiency $\left(\eta_{\mathrm{C}}\right)$ and corrected mass flow $\left(\mu_{\mathrm{C}}\right)$ and gas generator turbine efficiency $\left(\eta_{\mathrm{GGT}}\right)$.

Phase 3: Analysis of the Normalized Measurement Trend (Trend Analysis). The analysis is aimed at establishing relations among performance drops and normalized measurement trends of compressor outlet pressure $\left(p_{2}\right)$ and temperature $\left(T_{2}\right)$ and the power turbine outlet temperature $\left(T_{6}\right)$ reported in Figure 4.

Form Figure 4, a reduction of about $2 \%$ in 70 days on the trend of normalized compressor outlet pressure can be noticed, while compressor outlet temperature remains almost constant. These trends highlight a normal compressor fouling. The analysis of $T_{6}{ }^{*}$ alone, whose trend is slightly increasing, does not provide additional diagnostic information about the two turbines.

Phase 4: Gas Turbine Health State Determination. The percentage variation $E$ between computed and reference values of compressor efficiency $\left(\eta_{\mathrm{C}}\right)$ and corrected mass flow $\left(\mu_{\mathrm{C}}\right)$ HIs and of gas generator turbine efficiency HI ( $\left.\eta_{\mathrm{GGT}}\right)$ versus time is reported in Figure 5. The black and white symbols indicate the HIs evaluated by using the acceptable and unacceptable measurement sets, respectively.

Figure 5 highlights the decreasing trends of both compressor efficiency and mass flow function HIs, which can be attributed to compressor fouling, as already highlighted by the Trend Analysis in the previous section. Over a period of two months, the trend values of $\eta_{\mathrm{C}}$, and $\mu_{\mathrm{C}}$ HIs were reduced by $1.0 \%$ and $2.5 \%$, respectively, showing that fouling is not severe $[67,68]$. The trend of gas generator turbine efficiency $\mathrm{HI}$ is instead almost constant, indicating that this component is not suffering from significant changes in its health state. Figure 5 also highlights the remarkable reduction of the scattering of HI trends, obtainable by using the acceptable measurement sets only.

Phase 5-Gas Turbine Health State Determination on Multiple Operating Points. A multipoint analysis was also applied to the gas turbine unit considered by using measurements taken during special operating conditions, immediately before and after a maintenance stop. In these cases, measurements at different gas turbine loads were performed, so that it was possible to perform the multipoint analysis.

Two different calculations were performed by using different sets of variable HIs. In Figure 6(a), the normalized values of $\eta_{\mathrm{C}}, \mu_{\mathrm{C}}, \eta_{\mathrm{GGT}}$, and $\mu_{\mathrm{GGT}}$, calculated by using the multipoint analysis with three HIs $\left(\eta_{\mathrm{C}}, \mu_{\mathrm{C}}, \eta_{\mathrm{GGT}}\right)$ as problem variables, are reported. In Figure 6(b), the normalized values of $\eta_{\mathrm{C}}, \mu_{\mathrm{C}}, \eta_{\mathrm{GGT}}, \mu_{\mathrm{GGT}}, \eta_{\mathrm{PT}}$, and $\mu_{\mathrm{PT}}$, calculated by using the multipoint analysis with five HIs $\left(\eta_{\mathrm{C}}, \mu_{\mathrm{C}}, \eta_{\mathrm{GGT}}, \mu_{\mathrm{GGT}}\right.$, and $\left.\eta_{\mathrm{PT}}\right)$ as problem variables, are shown. Black and white symbols refer to the measurements taken before and after the maintenance stop, respectively. It can be highlighted how the multipoint analysis allows the determination of a number of HIs higher than available measured quantities, since it compensates for the lack of measured quantities with the measurements taken at different operating points.

The results obtained by using five HIs as problem variables (Figure 6(b)) seem more convincing than the ones obtained in the case of three variable HIs (Figure 6(a)). In 


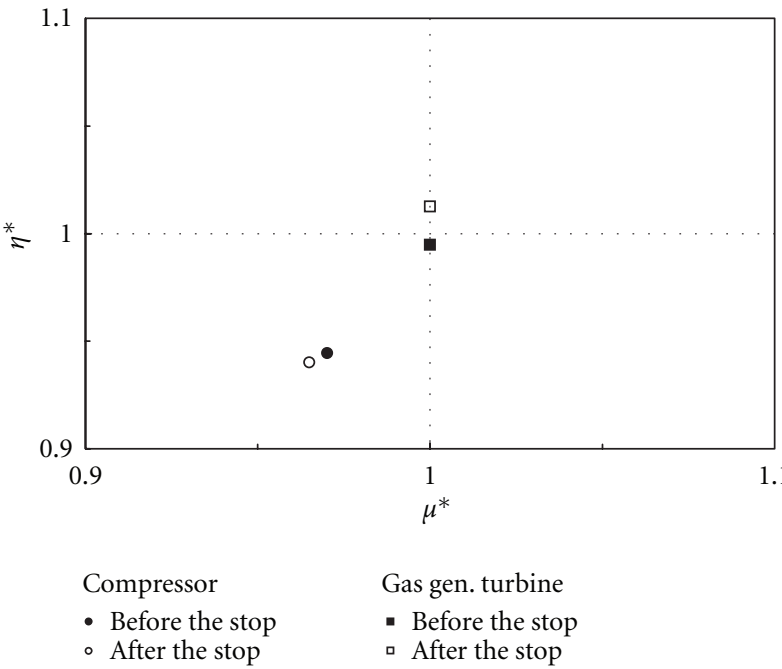

(a)
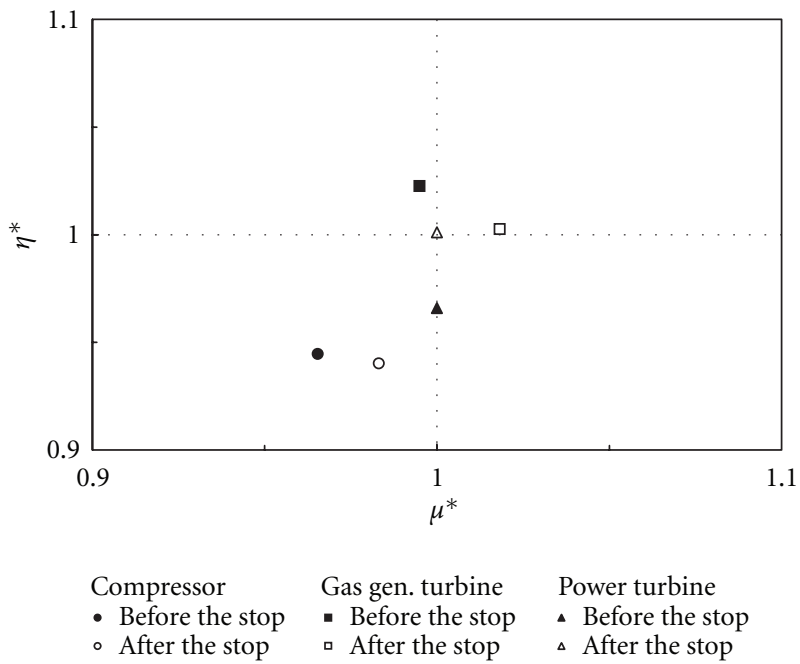

(b)

FiguRE 6: Normalized values of HIs in case of (a) three problem variables $\left(\eta_{\mathrm{C}}, \mu_{\mathrm{C}}\right.$, and $\left.\eta_{\mathrm{GGT}}\right)$, and (b) five problem variables $\left(\eta_{\mathrm{C}}, \mu_{\mathrm{C}}, \eta_{\mathrm{GGT}}\right.$, $\mu_{\mathrm{GGT}}, \eta_{\mathrm{PT}}$, and $\left.\mu_{\mathrm{PT}}\right)$ (multiple operating point analysis).

this last case, in fact, it seems that there are no improvements due to maintenance, while, in the case of five variable HIs, an increase in the compressor and gas generator turbine corrected mass flows HIs can be noticed.

\section{Software Tool for Gas Turbine On-Condition Monitoring and Diagnostics}

For the considered natural gas compression plant, a software tool was developed and implemented [57], to allow the prompt visualization of the required information by means of a user-friendly interface, so allowing gas turbine health state analysis and supporting the decision for maintenance actions.

The developed software, whose structure is sketched in Figure 7, allows

(i) the measurement normalization,

(ii) the calculation of HIs for the evaluation of gas turbine health state,

(iii) the comparison of the measured delivery of compressed natural gas compared with the calculated maximum possible delivery. This latter value is estimated by assuming the gas turbine in new and clean conditions.

Moreover, the software system stores all data in a database and calculates the trend line in order to perform the trend analysis for all the parameters.

The kernel of the software system consists of the subroutines that allow the manual insertion of data, data direct acquisition from the control system, the visualization of the results, and the modification of calculation parameters. The user interface is provided by means of floating toolbars (buttons and/or text).
Results can be displayed in form of graphs and tables, which allows a user-friendly interpretation of the results. The graphical form shows plots of calculated values and the corresponding trend lines versus time; acceptability bands are visualized around the trend line to evidence unacceptable data.

The program also determines the net power output of the gas turbine starting from measurements acquired on the centrifugal compressor, the overall gas turbine efficiency, and the turbine inlet temperature. The ratio between the actual and the nominal value for both the net power output and the turbine inlet temperature can be used as indices of the gas turbine overall health state.

Moreover, starting from the indices of the gas turbine health state, the software calculates the value of the production losses due to the actual health state. In fact, if $M_{\text {gasM }}$ is the measurement of the natural gas flow rate processed by the centrifugal compressor and $M_{\mathrm{gasC}}$ the flow rate that the centrifugal compressor could process when the driving gas turbine is in new and clean conditions, a lost production index LPI can be calculated as

$$
\mathrm{LPI}=\frac{M_{\mathrm{gasC}}-M_{\mathrm{gasM}}}{M_{\mathrm{gaSC}}}
$$

In Figure 8 a sample trend of LPI is reported. The trend is increasing due to gas turbine ageing: in fact, the more the gas turbine deterioration increases (and, thus, its performances decrease), the more the gas flow rate that the centrifugal compressor can process $\left(M_{\mathrm{gasM}}\right)$ reduces.

In conclusion, the software can actually represent a helpful support tool for the plant operation management. The persons which can take advantage of these analyses can be

(i) the plant manager; In fact LPI evaluation allows useful information on the actual economical benefit 


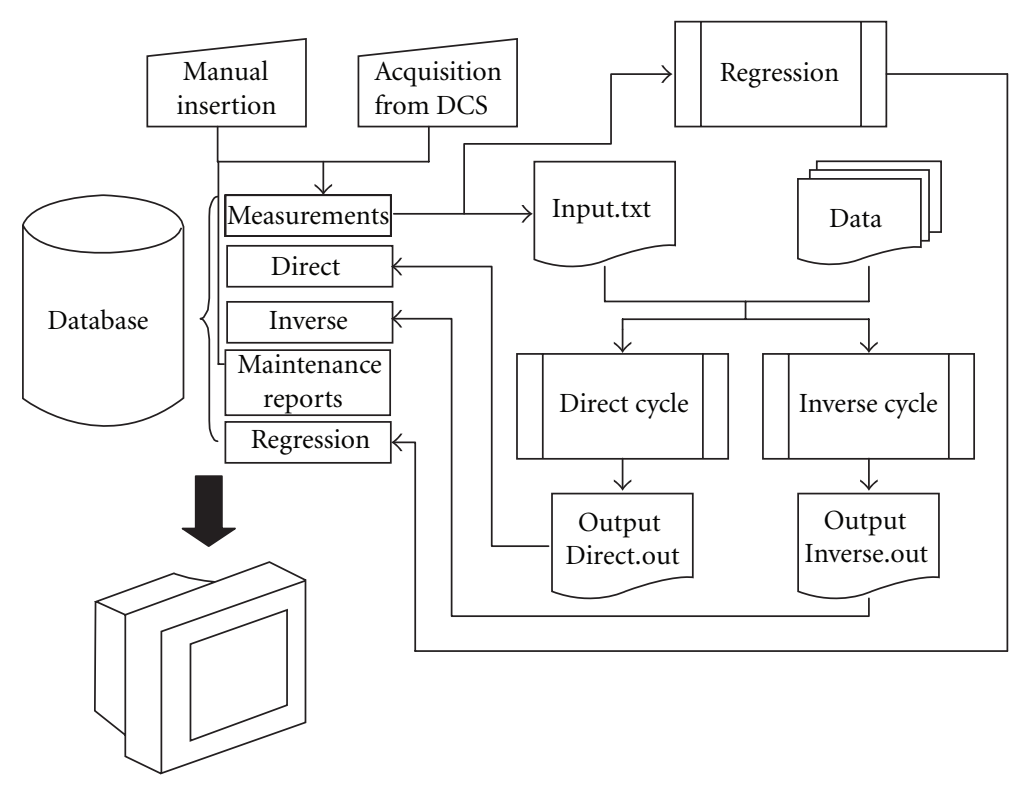

FIGURE 7: Software system architecture.

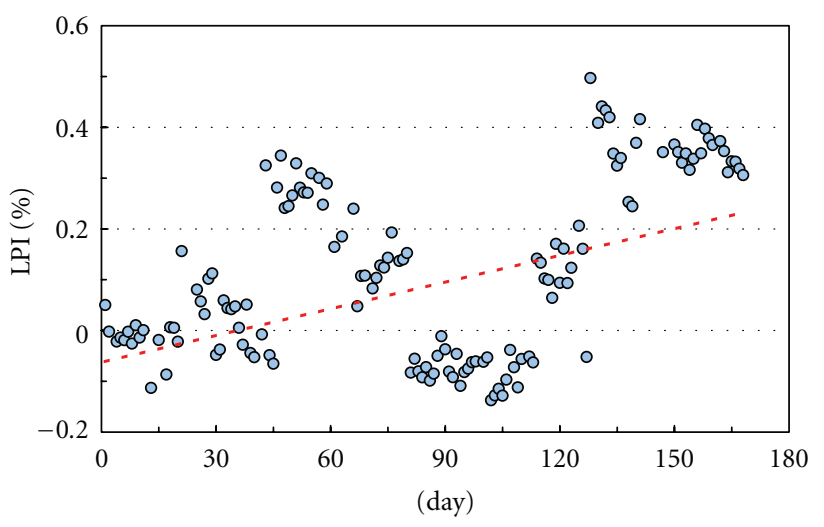

FIgURE 8: Lost production index trend.

of keeping the plant in operation rather than stop it to perform maintenance actions,

(ii) the maintenance manager, which, through the analysis of the normalized measurement and of the HIs trends, can obtain information on overall performance deterioration, on the components that are responsible for the deterioration, on the type and on the quantification of the deterioration;

(iii) the maintenance chief engineer, which, still through the analysis of the normalized measurement and of HIs trends, can obtain information on the performance recovery after maintenance actions.

\section{Conclusions}

In this paper, a comprehensive methodology for both measurement validation and health state determination of gas turbines was presented, discussed, and applied to a $5 \mathrm{MW}$ gas turbine working in a natural gas compression plant.
The methodology demonstrated to be effective in supporting plant operation and maintenance management and some interesting results were presented. In particular.

(i) The application of the methodologies for measurement validation allowed the identification of outliers, the elimination of which allowed a remarkable reduction of the scattering of the trend-over-time of the measurements. The measurement sets composed of outliers were not used for estimating machine health indices.

(ii) Gas turbine health state determination, performed by applying the developed gas path analysis technique over a working period of two months, highlighted that compressor fouling (though not severe) was occurring, while gas generator turbine was not suffering from significant changes in health state.

(iii) The application of the multipoint analysis to measurements taken immediately before and after a maintenance stop allowed a more detailed analysis of the health state of the main gas turbine components.

Finally, the main features of a software, which was implemented in the considered compression plant to automate the diagnostic process and to support plant operation and management, were presented. As a sample application, the loss of production, due to gas turbine deterioration, was reported.

\section{Nomenclature}

E: Variation

$F$ : $\quad$ Map scaling factors

$F_{\mathrm{ob}}: \quad$ Objective function

$k, k_{A}, k_{B}$ : Test criterion coefficients 
LPI: Loss of production index

M: $\quad$ Mass flow rate

$N$ : Sample size, rotational speed

$N_{m}$ : Dimension of $Q_{m}$ vector

$N_{\text {op }}$ : Number of operating points

$N_{x}$ : Dimension of $X$ vector

$P: \quad$ Total pressure

$P$ : $\quad$ Power

$Q_{m}$ : Vector of measured variables

$Q_{m, c}$ : Vector of computed estimates of the measured variables

$Q_{w p}$ : Vector of measured variables necessary to define the working point

RH: Relative humidity

S: $\quad$ Standard deviation of the sample

T: $\quad$ Total temperature

$t_{\alpha}$ : T-student distribution quantile

VN: Variable nozzle angular position

w: Weight

$x$ : element of the sample

$X: \quad\left[X_{1}, \ldots, X_{N x}\right]^{T}$ vector of health indices

$\alpha$ : Level of significance

$\Delta$ : Variation

$\eta: \quad$ efficiency

$\mu: \quad=M \sqrt{T} / p$ mass flow function

*: $\quad$ Normalized value.

\section{Subscripts}

$\begin{array}{ll}a: & \text { Ambient } \\ \text { C: } & \text { Compressor } \\ f: & \text { Fuel } \\ m: & \text { Mean value }\end{array}$

GGT: Gas generator turbine

GasC: Compressed gas (calculated)

GasM: Compressed gas (measured)

ov: Overall

PT: $\quad$ Power turbine.

Acronyms

$\begin{array}{ll}\text { C: } & \text { Compressor } \\ \text { CC: } & \text { Combustion chamber } \\ \text { CP: } & \text { Cycle Program } \\ \text { F: } & \text { Filter } \\ \text { GGT: } & \text { Gas generator turbine } \\ \text { GPA: } & \text { Gas path analysis } \\ \text { HI: } & \text { Health index } \\ \text { PT: } & \text { Power turbine. }\end{array}$

\section{References}

[1] R. F. Hoeft, "Heavy duty gas turbine operating and maintenance considerations," in Proceedings of the 39th GE Turbine State-of-the-Art Technology Seminar, GER-3620D, 1996.

[2] T. P. Schmitt and C. G. Petroff, "Gas turbine performance monitoring and testing," in Proceedings of the 39th GE Turbine State-of-the-Art Technology Seminar, GER-3958, 1996.
[3] R. Bettocchi, M. Pinelli, P. R. Spina, M. Venturini, and S. Sebastianelli, "A system for health state determination of natural gas compression gas turbines," in Proceedings of the Turbine Technical Conference and Exposition, ASME Paper 2001-GT-223, 2001.

[4] D. Therkorn, "Remote monitoring \& diagnostic for combined-cycle power plants," in Proceedings of the Turbine Technical Conference and Exposition, ASME Paper GT2005-68710, pp. 697-703, June 2005.

[5] H. R. Depold and J. Siegel, "Using diagnostics and prognostics to minimize the cost of ownership of gas turbines," in Proceedings of the Turbine Technical Conference and Exposition, ASME Paper GT2006-91183, pp. 845-851, May 2006.

[6] E. Hindle, R. Van Stone, C. Brogan, J. Vandike, K. Dale, and N. Gibson, "A prognostic and diagnostic approach to engine health management," in Proceedings of the Turbine Technical Conference and Exposition, ASME Paper GT2006-90614, pp. 673-680, May 2006.

[7] L. C. Jaw, "Recent advancements in aircraft Engine Health Management (EHM) technologies and recommendations for the next step," in Proceedings of the Turbine Technical Conference and Exposition, ASME Paper GT2005-68625, pp. 683695, June 2005.

[8] L. A. Urban, "Gas path analysis applied to turbine engine condition monitoring," in Proceedings of the AIAA/SAE 8th Joint Propulsion Conference, New Orleans, La, USA, 1972.

[9] A. Stamatis, K. Mathioudakis, and K. D. Papailiou, "Adaptive simulation of gas turbine performance," ASME Journal of Engineering for Gas Turbines and Power, vol. 112, pp. 168-175, 1990.

[10] E. Benvenuti, R. Bettocchi, G. Cantore, G. Negri di Montenegro, and P. R. Spina, "Gas turbine cycle modeling oriented to component performance evaluation from limited design or test data," in Proceedings of the 7th ASME COGEN-TURBO, vol. 8, pp. 327-337, IGTI, Bournemouth, UK, 1993.

[11] E. Benvenuti, R. Bettocchi, G. Cantore, G. Negri di Montenegro, and P. R. Spina, "Experimental validation of a gas turbine cycle model based on a simultaneous solution method," in Proceedings of the 8th ASME COGEN-TURBO, vol. 9, pp. 245255, IGTI, Portland, Ore, USA, 1994.

[12] R. Bettocchi and P. R. Spina, "Diagnosis of gas turbine operating conditions by means of the inverse cycle calculation," in Proceedings of the Turbine Technical Conference and Exposition, ASME Paper 99-GT-185, 1999.

[13] R. Bettocchi, M. Pinelli, P. R. Spina, and M. Venturini, "Artificial intelligence for the diagnostics of gas turbines-part 1: neural network approach," Journal of Engineering for Gas Turbines and Power, vol. 129, no. 3, pp. 711-719, 2007.

[14] R. Bettocchi, M. Pinelli, P. R. Spina, and M. Venturini, "Artificial intelligence for the diagnostics of gas turbines-part II: neuro-fuzzy approach," Journal of Engineering for Gas Turbines and Power, vol. 129, no. 3, pp. 720-729, 2007.

[15] R. Bettocchi, M. Pinelli, P. R. Spina, M. Venturini, and G. A. Zanetta, "Assessment of the robustness of gas turbine diagnostics tools based on neural networks," in Proceedings of the Turbine Technical Conference and Exposition, ASME Paper GT2006-90118, pp. 603-613, May 2006.

[16] M. Bianchi, A. Peretto, and P. R. Spina, "Modular dynamic model of multi-shaft gas turbine and validation test," in Proceedings of the Winter Annual Meeting of ASME, vol. 38, pp. 73-81, AES, Anaheim, Calif, USA, 1998.

[17] M. Venturini, "Development and experimental validation of a compressor dynamic model," Journal of Turbomachinery, vol. 127, no. 3, pp. 599-608, 2005. 
[18] M. Morini, M. Pinelli, and M. Venturini, "Development of a one-dimensional modular dynamic model for the simulation of surge in compression systems," Journal of Turbomachinery, vol. 129, no. 3, pp. 437-447, 2007.

[19] M. Morini, M. Pinelli, and M. Venturini, "Application of a one-dimensional modular dynamic model for compressor surge avoidance," in Proceedings of the Turbine Technical Conference and Exposition, ASME Paper GT2007-27041, pp. 14251434, May 2007.

[20] M. Morini, G. Cataldi, M. Pinelli, and M. Venturini, "A model for the simulation of large-size single-shaft gas turbine startup based on operating data fitting," in Proceedings of the Turbine Technical Conference and Exposition, ASME Paper GT2007-27373, pp. 1849-1856, May 2007.

[21] M. Morini, M. Pinelli, and M. Venturini, "Analysis of biogas compression system dynamics," Applied Energy, vol. 86, no. 11, pp. 2466-2475, 2009.

[22] M. Venturini, "Simulation of compressor transient behavior through recurrent neural network models," Journal of Turbomachinery, vol. 128, no. 3, pp. 444-454, 2006.

[23] M. Venturini, "Optimization of a real-time simulator based on recurrent neural networks for compressor transient behavior prediction," Journal of Turbomachinery, vol. 129, no. 3, pp. 468-478, 2007.

[24] M. Pinelli, P. R. Spina, and M. Venturini, "Optimized operating point selection for gas turbine health state analysis by using a multi-point technique," in Proceedings of the Turbine Technical Conference and Exposition, ASME Paper GT200338191, pp. 43-51, June 2003.

[25] Y. G. Li, "Gas turbine diagnosis using a fault isolation enhanced GPA," in Proceedings of the Turbine Technical Conference and Exposition, pp. 361-369, June 2004.

[26] A. I. Zwebek and P. Pilidis, "Application of GPA to combined cycle gas turbine plants," in Proceedings of the Turbine Technical Conference and Exposition, ASME Paper GT2004-53026, pp. 225-232, June 2004.

[27] O. Córdoba, "Gas path analysis study for overhaul engines," in Proceedings of the Turbine Technical Conference and Exposition, ASME Paper GT2005-68137, pp. 497-505, June 2005.

[28] M. Morini, M. Pinelli, P. R. Spina, and M. Venturini, "Influence of blade deterioration on compressor and turbine performance," Journal of Engineering for Gas Turbines and Power, vol. 132, no. 3, Article ID 032401, 2010.

[29] P. R. Spina, "Gas turbine performance prediction by using generalized performance curves of compressor and turbine stages," in Proceedings of the Turbine Technical Conference and Exposition, ASME Paper GT-2002-30275, pp. 1073-1082, June 2002.

[30] M. Bagnoli, M. Bianchi, F. Melino, and P. R. Spina, "Development and validation of a computational code for wet compression simulation of gas turbines," Journal of Engineering for Gas Turbines and Power, vol. 130, no. 1, Article ID 012004, 2008.

[31] M. Bagnoli, M. Bianchi, F. Melino et al., "Application of a computational code to simulate interstage injection effects on GE frame 7EA gas turbine," Journal of Engineering for Gas Turbines and Power, vol. 130, no. 1, Article ID 012001, 2008.

[32] M. Morini, M. Pinelli, P. R. Spina, and M. Venturini, "Computational fluid dynamics simulation of fouling on axial compressor stages," Journal of Engineering for Gas Turbines and Power, vol. 132, no. 7, Article ID 072401, 2010.

[33] M. Morini, M. Pinelli, P. R. Spina, and M. Venturini, "Numeri$\mathrm{cal}$ analysis of the effects of non-uniform surface roughness on compressor stage performance," Journal of Engineering for Gas Turbines and Power, vol. 133, no. 7, Article ID 072402, 2011.
[34] M. Pinelli, M. Morini, P. R. Spina, M. Venturini, and C. Ferrari, "Analysis of the effects of simulated fouling on an axial compressor stage through CFD modeling," in Proceedings of the 9th European Conference on Turbomachinery, M. Sen, G. Bois, M. Manna, and T. Arts, Eds., vol. 1, pp. 261-270, Istanbul, Turkey, 2011.

[35] F. Melino, M. Morini, A. Peretto, M. Pinelli, and P. R. Spina, "Compressor fouling modeling: relationship between computational roughness and gas turbine operation time," in Proceedings of the Turbine Technical Conference and Exposition, ASME Paper GT2011-46089, 2011.

[36] R. Bettocchi, M. Pinelli, and P. R. Spina, "A multistage compressor test facility: uncertainty analysis and preliminary test results," Journal of Engineering for Gas Turbines and Power, vol. 127, no. 1, pp. 170-177, 2005.

[37] M. Morini, M. Pinelli, and M. Venturini, "Acoustic and vibrational analyses on a multi-stage compressor for unstable behaviour precursor identification," in Proceedings of the Turbine Technical Conference and Exposition, ASME Paper GT200727040, pp. 1415-1423, May 2007.

[38] R. Bettocchi, M. Morini, M. Pinelli, P. R. Spina, M. Venturini, and G. Torsello, "Setup of an experimental facility for the investigation of wet compression on a multistage compressor," Journal of Engineering for Gas Turbines and Power, vol. 133, no. 10, Article ID 102001, 2011.

[39] R. Bettocchi, P. R. Spina, and E. Benvenuti, "Set-up of an adaptive method for the diagnosis of gas turbine operating state by using test-Bench measurements," in Proceedings of the Turbine Technical Conference and Exposition, ASME Paper 2000-GT-0309, 2000.

[40] A. Stamatis, K. Mathioudakis, and K. Papailiou, "Optimal measurement and health index selection for gas turbine performance status and fault diagnosis," Journal of Engineering for Gas Turbines and Power, vol. 114, no. 2, pp. 209-216, 1992.

[41] M. Pinelli and P. R. Spina, "Gas turbine field performance determination: sources of uncertainties," Journal of Engineering for Gas Turbines and Power, vol. 124, no. 1, pp. 155-160, 2002.

[42] Y. G. Li, P. Pilidis, and M. A. Newby, "An adaptation approach for gas turbine design-point performance simulation," in Proceedings of the Turbine Technical Conference and Exposition, pp. 95-105, usa, June 2005.

[43] M. Pinelli and M. Venturini, "Improvement of the accuracy in gas turbine health determination," in Proceedings of the Turbine Technical Conference and Exposition, ASME Paper 2001-GT-476, 2001.

[44] M. Pinelli, M. Venturini, and M. Burgio, "Statistical methodologies for reliability assessment of gas turbine measurements," in Proceedings of the Turbine Technical Conference and Exposition, ASME Paper GT2003-38407, pp. 787-793, June 2003.

[45] H. DePold, A. Volponi, J. Siegel, and J. Hull, "Validation of diagnostic data with statistical analysis and embedded knowledge," in Proceedings of the Turbine Technical Conference and Exposition, ASME Paper 2003-GT-38764, pp. 573-579, June 2003.

[46] P. C. Chen and H. Andersen, "The implementation of the data validation process in a gas turbine performance monitoring system," in Proceedings of the Turbine Technical Conference and Exposition, ASME Paper GT2005-68429, pp. 609-616, June 2005.

[47] P. Hartner, J. Petek, P. Pechtl, and P. Hamilton, "Modelbased data reconciliation to improve accuracy and reliability of performance evaluation of thermal power plants," in 
Proceedings of the Turbine Technical Conference and Exposition, ASME Paper GT2005-68937, pp. 195-200, June 2005.

[48] S. C. Gulen and R. W. Smith, "A simple mathematical approach to data reconciliation in a single-shaft combined-cycle system," in Proceedings of the Turbine Technical Conference and Exposition, ASME Paper GT2006-90145, pp. 479-491, May 2006.

[49] K. Mathioudakis and P. Kamboukos, "Assessment of the effectiveness of gas path diagnostic schemes," in Proceedings of the Turbine Technical Conference and Exposition, ASME Paper GT2004-53862, pp. 723-731, June 2004.

[50] S. W. Butler, K. R. Pattipati, A. Volponi, J. Hull, R. Rajamani, and J. Siegel, "An assessment methodology for data-driven and model-based techniques for engine health monitoring," in Proceedings of the Turbine Technical Conference and Exposition, ASME Paper GT2006-91096, pp. 823-831, May 2006.

[51] C. Romessis, P. Kamboukos, and K. Mathioudakis, "The use of probabilistic reasoning to improve least squares based gas path diagnostics," in Proceedings of the Turbine Technical Conference and Exposition, ASME Paper GT2006-90619, pp. 681-689, May 2006.

[52] R. Bettocchi, M. Pinelli, P. R. Spina, and M. Venturini, "Statistical analyses to improve gas turbine diagnostics reliability," in Proceedings of the IGTC, Paper IGTC2003-Tokyo TS-004, 2003.

[53] M. Pinelli and M. Venturini, "Operating state historical data analysis to support gas turbine malfunction detection," in Proceedings of the Turbine Technical Conference and Exposition, ASME IMECE2001/AES-23665, pp. 457-462, November 2001.

[54] P. R. Spina, "Reliability in the determination of gas turbine operating state," in Proceedings of the 39th IEEE Conference on Decision and Control, Paper CDC00-INV5805, Sydney, Australia, 2000.

[55] R. Bettocchi, M. Pinelli, M. Venturini, P. R. Spina, S. Bellagamba, and G. Tirone, "Procedura di calibrazione del programma per la diagnosi funzionale dei turbogas della centrale a ciclo combinato di la spezia," in Proceedings of the Atti del 57th Congresso Nazionale ATI, Pisa, Italy, 2002.

[56] A. Gulati, M. Zedda, and R. Singh, "Gas turbine engine and sensor multiple operating point analysis using optimization techniques," in Proceedings of the 36th AIAA/ASME/ SAE/ASEE Joint Propulsion Conference and Exhibit, AIAA 2000-3716, 2000.

[57] R. Bettocchi, M. Pinelli, M. Venturini, P. R. Spina, S. Sebastianelli, and F. Bezzi, "A software tool for gas turbine oncondition monitoring and diagnostics," in Proceedings of OMC The Mediterranean: New Oil and Gas Routes for an Ancient Sea, Ravenna, Italy, 2003.

[58] P. R. Spina, G. Torella, and M. Venturini, "The use of expert systems for gas turbine diagnostics and maintenance," in Proceedings of the Turbine Technical Conference and Exposition, ASME Paper GT-2002-30033, pp. 127-134, June 2002.

[59] N. Puggina and M. Venturini, "Development of a statistical methodology for gas turbine prognostics," in Proceedings of the Turbine Technical Conference and Exposition, ASME Paper GT2011-45708, 2011.

[60] A. Cavarzere and M. Venturini, "Application of forecasting methodologies to predict gas turbine behavior over time," in Proceedings of the Turbine Technical Conference and Exposition, ASME Paper GT2011-45708, 2011.

[61] R. Bettocchi, P. R. Spina, M. Pinelli, M. Venturini, and M. Burgio, "Set up of a robust neural network for gas turbine simulation," in Proceedings of the Turbine Technical Conference and Exposition, ASME Paper GT2004-53421, pp. 543-551, June 2004.

[62] P. R. Spina and M. Venturini, "Gas turbine modeling by using neural networks trained on field operating data," in Proceedings of the ECOS, vol. 1, pp. 213-222, Padova, Italy, 2007.

[63] Visual Numerics, Inc., "IMSL MATH/LIBRARY: FORTRAN Subroutines for Mathematical Applications," Houston, Texas, USA, 1994.

[64] R. Bettocchi, P. R. Spina, and S. Alliney, "Resolution method for gas turbine mathematical models," in Proceedings of the 8th ASME COGEN-TURBO, vol. 9, pp. 361-369, Portland, Ore, USA, 1994.

[65] M. Pinelli and M. Venturini, "Application of methodologies to evaluate the health state of gas turbines in a cogenerative combined cycle power plant," in Proceedings of the Turbine Technical Conference and Exposition, ASME Paper GT-200230248, pp. 187-195, June 2002.

[66] ISO 2314, "Gas Turbine-Acceptance Tests," International Standard, 1989.

[67] I. S. Diakunchak, "Performance deterioration in industrial gas turbines," Journal of Engineering for Gas Turbines and Power, vol. 114, no. 2, pp. 161-168, 1992.

[68] H. I. H. Saravanamuttoo and B. D. Maclsaac, "Thermodynamic models for pipeline gas turbine diagnostics," Journal of Engineering for Power, vol. 105, no. 4, pp. 875-884, 1983. 

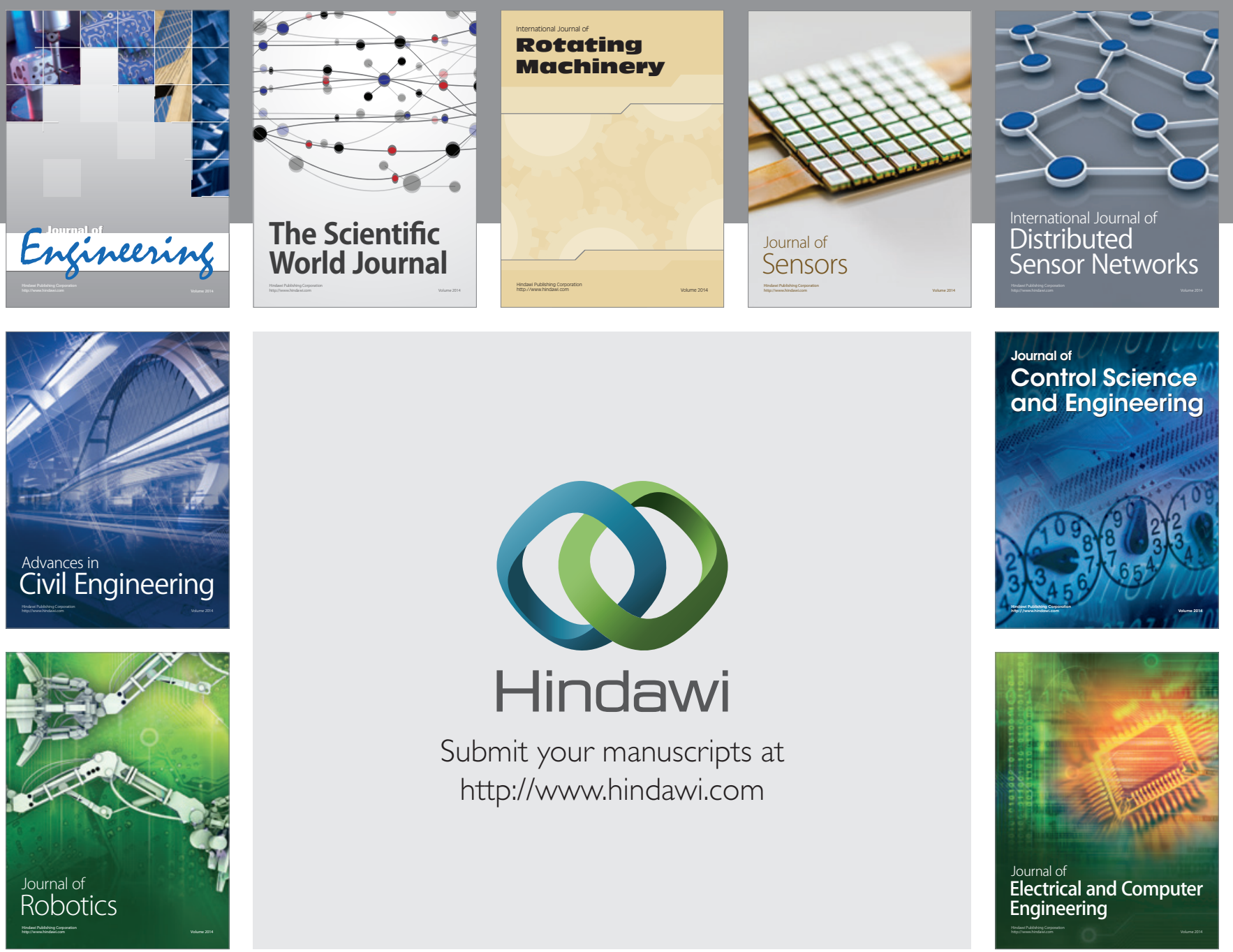

Submit your manuscripts at

http://www.hindawi.com
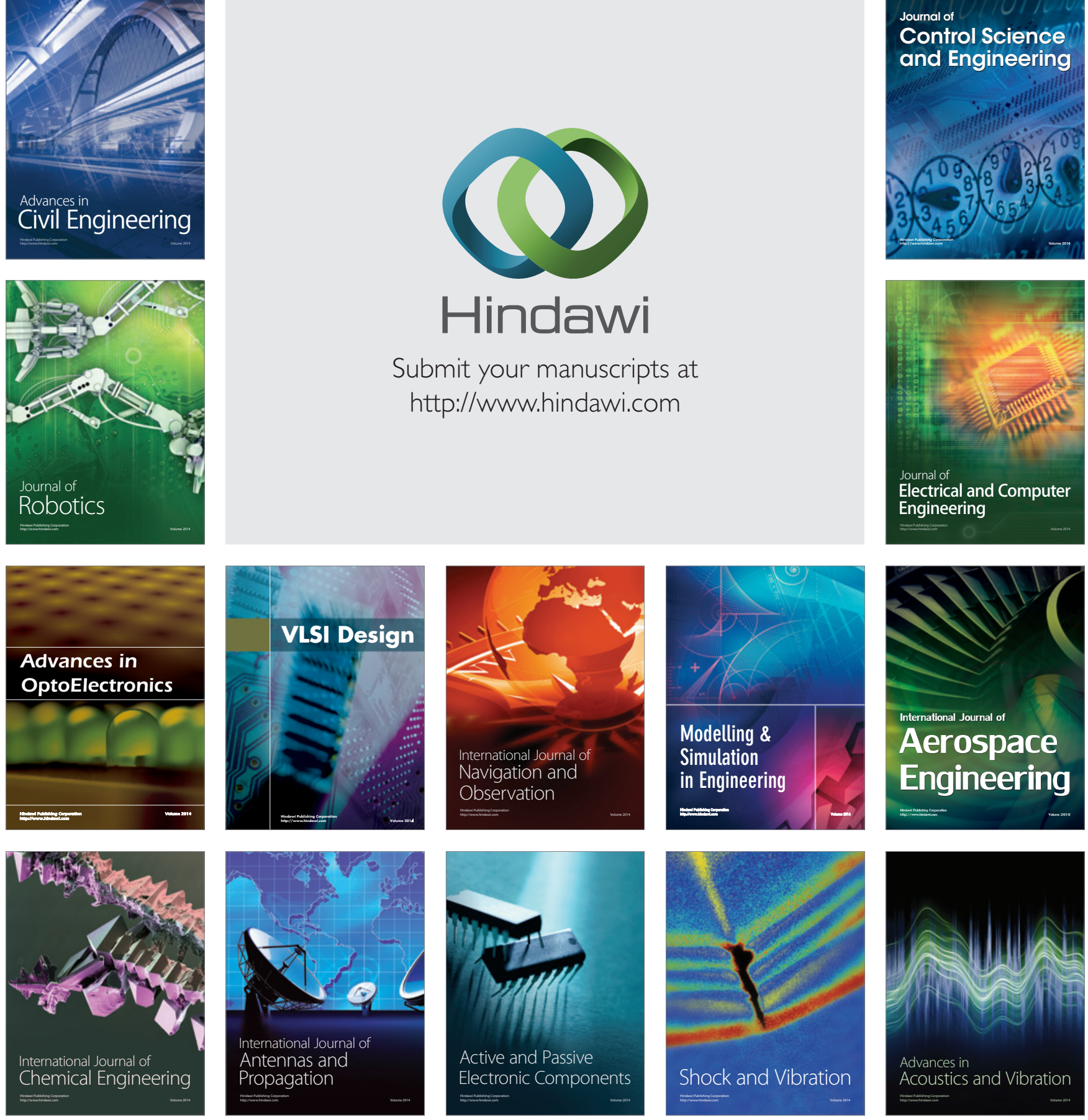